\title{
GaAs laser therapy reestablishes the morphology of the NMJ and nAChRs after injury due to bupivacaine
}

\author{
Cristiane Neves Alessi Pissulin a,b,*, Paula Aiello Tomé de Souza Castro c, Flávio Codina ${ }^{\mathrm{d}}$, Carina Guidi Pinto ${ }^{\mathrm{e}}$, \\ Ivan Jose Vechetti-Junior ${ }^{\mathrm{f}}$, Selma Maria Michelin Matheus ${ }^{\mathrm{g}, \mathrm{h}}$ \\ a Department of Anatomy, Universidade do Oeste Paulista (UNOESTE), Presidente Prudente, SP, Brazil \\ b General Bases of Surgery, Botucatu Medical School, UNESP, Botucatu, SP, Brazil \\ c Departament of Physical Therapy, Center for Biologic Sciences and Health - CBSH, Federal University of São Carlos/UFSCar/São Carlos, SP, Brazil \\ d Sciences Student, UNESP, Institute of Biosciences, Botucatu, SP, Brazil \\ e Department of Anatomy, Institute of Biosciences, São Paulo State University (UNESP), Botucatu, SP, Brazil \\ ${ }^{\mathrm{f}}$ Department of Morphology, Institute of Biosciences, São Paulo State University (UNESP), Botucatu, SP, Brazil \\ ${ }^{g}$ Department of Anatomy, Institute of Biosciences, General Bases of Surgery, Botucatu Medical School, Brazil \\ ${ }^{\text {h }}$ UNESP, Botucatu, SP, Brazil
}

\section{A R T I C L E I N F O}

\section{Article history:}

Received 20 September 2016

Accepted 19 December 2016

Available online 22 December 2016

\section{Keywords:}

Bupivacaine

Low-level light therapy

Neuromuscular junction

Nicotinic acetylcholine receptor

\begin{abstract}
A B S T R A C T
Background: Local anesthetics are used to relieve pre- and postoperative pain, acting on both sodium channels and nicotinic acetylcholine receptors (nAChR) at the neuromuscular junction (NMJ). Bupivacaine acts as a non-competitive antagonist and has limitations, such as myotoxicity, neurotoxicity, and inflammation. Lowlevel laser therapy (LLLT) has anti-inflammatory, regenerative, and analgesic effects. The aim of the present study was to evaluate the effects of a gallium arsenide laser (GaAs) on the morphology of the NMJ and nAChRs after application of bupivacaine in the sternomastoid muscle.

Methods: Thirty-two adult male Wistar rats received injections of bupivacaine $0.5 \%$ (Bupi: right antimere) and $0.9 \%$ sodium chloride ( $\mathrm{Cl}$ : left antimere). Next, the animals were divided into a Control group (C) and a Laser group (LLLT). The laser group received LLLT (GaAs $904 \mathrm{~nm}, 50 \mathrm{~mW}, 4,8 \mathrm{~J}$ ) in both antimeres for five consecutive days. After seven days, the animals were euthanized and the surface portion of the sternomastoid muscle was removed, frozen, and subjected to morphological and morphometric analyses of the NMJs (nonspecific esterase reaction), confocal laser scanning, and an ultrastructural analysis. The nAChRs were quantified by Western blotting. Results: In the chloride group, the morphology and morphometry of the NMJs remained stable. The maximum diameters of the NMJs were lower in the Bupi (15.048 \pm 1.985$)$ and LLLT/Bupi subgroups (15.456 \pm 1.983$)$ compared to the $\mathrm{Cl}(18.502 \pm 2.058)$ and LLLT/Cl subgroups $(19.356 \pm 2.522)(p<0.05)$. Ultrastructurally, LLLT reduced myonecrosis observed after application of bupivacaine, with recovery in the junctional folds and active zone. There was an increase in the perimeter of the LLLT/Bupi subgroup (150.33) compared to the Bupi subgroup (74.69) $(p<0.01)$ observed by confocal microscopy. There was also an increase in the relative planar area of the NMJ after LBI (8.75) compared to CBupi $(4.80)(p<0.01)$. An analysis of the protein expression of $\mathrm{nAChR} \alpha 1$ showed no major differences in the groups studied. There was an increase in protein expression of the $\varepsilon$ subunit after application of LLLT (13.055) compared to Bupi $(0.251)(p<0.01)$. Taken together, the present experiments indicate that there was a positive association of the $\alpha$ and $\gamma$ subunits $(p<0.05)$.

Conclusions: These results demonstrate that LLLT at the dose used in this study reduced structural alterations in the NMJ and molecular changes in nAChRs triggered by bupivacaine, providing important data supporting the use of LLLT in therapeutic protocols for injuries triggered by local anesthetics.
\end{abstract}

(c) 2016 Elsevier B.V. All rights reserved.

\footnotetext{
* Corresponding author at: Departamento de Anatomia, Faculdade de odontologia, Rua José Bongiovanni, 700, Cep 18050-680, Unoeste, Campus I/Presidente Prudente/SP, Brazil.

E-mail addresses: crispissulin@gmail.com (C.N.A. Pissulin), paula.soupat@gmail.com (P.A.T. de Souza Castro), flavio_codina@hotmail.com (F. Codina), carina_guidi@hotmail.com (C.G. Pinto), ijvechetti@gmail.com (I.J. Vechetti-Junior), micmath@ibb.unesp.br (S.M.M. Matheus).
}

\section{Introduction}

Local anesthetics are chemical agents that act by reversibly blocking peripheral nerve conduction [1-3].

These substances are widely used during medical and dental surgical procedures with the aim of achieving a safer and more comfortable 
procedure for patients [4-10], as well as the relief of postoperative pain. They are also used to treat chronic pain [11-16].

The structural and physicochemical characteristics of local anesthetics can be determining factors for their different effects [17]. These drugs act on both the voltage-dependent sodium channels (in axons) and nAChRs (acetylcholine receptors) of the NMJ [18-20]. The muscular acetylcholine receptor (AChR) is a heteropentamer composed of four polypeptide chains containing two alpha $(\alpha 1)$, one beta $(\beta)$, one delta $(\delta)$ and one gamma subunit $(\gamma)$. The latter subunit, present in embryonic or denervated fibers, is replaced in adult muscle fibers and innervated by the epsilon subunit $(\varepsilon)$. These five subunits are organized around a central ion-conducting pore that is permeable to cations [21].

NAChRs play a key role in the peripheral nervous system, are concentrated in the apex of the junctional folds of the postsynaptic membrane of the neuromuscular junction (NMJ) [22], and have been the target of interest for the development of new drugs, for example, for disorders of the peripheral nervous system [23-26]. There are numerous pharmacological substances that selectively alter the conformation of nAChRs [21]. Bupivacaine is a chemical substance that acts as a noncompetitive antagonist that can block the opening of the ion channel or an allosteric site of the nAChRs of the NMJ, inhibiting it, thus blocking muscle contraction [19]. This anesthetic is associated with adverse reactions leading to a rapid necrosis of muscle fibers [27-28], as well as alterations in the morphological and structural characteristics of the NMJs [28-29].

One of the principle obstacles to the development of new drugs is the presence of side effects. In this context, Low-level Laser Therapy (LLLT) has been shown to be a non-invasive clinical procedure that is easy to apply, low cost, lacks mutagenic effects, and risk-free [30-32]. In addition, it has anti-inflammatory, regenerative, and analgesic actions [33-36]. The electrophysiological effects of an LLLT $830 \mathrm{~nm}$ laser diode were examined on neuromuscular synaptic transmission and a reduction in ACh release at the physiological level was found [37]. This modulation of synaptic transmission may be related to the muscle relaxant effect of this type of laser. The therapeutic potential of LLLT was described in preventing an increase in nAChRs resulting from muscle atrophy after denervation [38].

Bupivacaine is highly lipophilic, and its neuro- and myotoxic effects are directly related to the uncoupling of oxidative phosphorylation, with inhibition of ATP synthesis of the mitochondrial respiratory chain [39]. However, there is evidence that LLLT increases the synthesis of ATP [39-40], with cytochrome $c$ oxidase being a photo target [41-42]. LLLT also leads to a reciprocal increase in oxygen consumption [40].

Considering that bupivacaine is an anesthetic that is used on a large scale and that its action directly involves the components of muscle synapses, the purpose of this study was to investigate the possibility that LLLT might preserve or protect the morphology of the NMJ and nAChRs following exposure to bupivacaine.

\section{Methodology}

\subsection{Animals}

This study was approved by the Ethics Committee on Animal. Use of the Institute of Biosciences, UNESP, Botucatu (protocol no. 509-CEUA/ IBB).

Thirty-two adult male Wistar rats, with an average weight of $300 \mathrm{~g}$, were obtained from the Central Animal Laboratory of Unesp in Botucatu. The animals were maintained in individual cages in a controlled environment, with feed and water provided ad libitum, and the room temperature maintained at $24 \pm 2{ }^{\circ} \mathrm{C}$, with a $12 \mathrm{~h}: 12 \mathrm{~h}$ photoperiod.

\subsection{Experimental Protocol and Treatment Parameters}

Initially, the animals were intraperitoneally (i.p.) anesthetized with ketamine/xylazine ( $90 \mathrm{mg} / \mathrm{kg}$ and $10 \mathrm{mg} / \mathrm{kg}$ ). After trichotomy, a median incision was made on the ventral surface of the neck and the sternomastoid muscles were exposed. Subfascial injections of $0.5 \%$ bupivacaine and $0.9 \%$ sodium chloride were applied to the middle [43] and distal thirds of muscles pertaining to the right and left antimeres, respectively. This protocol followed the method used for induction of degeneration-regeneration of muscle fibers by local anesthetics [23,44-46].

Next, the skin was sutured with black Nylon no. 3.0 (Brasutura ${ }^{\circledR}$ ). The animals were kept under heaters until they recovered; then, they received a single $100 \mu \mathrm{l}$ dose of sodium dipyrone solution.

Twenty-four hours after treatment, the animals were randomly divided into two groups, a Control group: right antimere (Bupi) and left antimere $(\mathrm{Cl})$, and a Laser group: right antimere (LLLT/Bupi) and left antimere (LLLT/Cl).

A previously calibrated laser diode composed of gallium arsenide (GaAs) with a pulsed emission at904 $\mathrm{nm}(50 \mathrm{~mW})$ was applied directly to the skin (direct contact) with a beam emission area of $0.035 \mathrm{~cm}^{2}$, corresponding to the areas of injections, in both antimeres, for five consecutive days. The pen was held at an angle $90^{\circ}$ to the irradiated surface to prevent leakage of the emitted light. The applications lasted $48 \mathrm{~s}$, with an energy of $2.4 \mathrm{~J}$ per point, providing a total final energy of $4.8 \mathrm{~J}$. Twenty-four hours after the final laser application (day 7), the animals were euthanized by i.p. injection of excess anesthetic (ketamine/xylazine).

\subsubsection{Morphological and Morphometric Analysis of the Neuromuscular Junction (NMJ) Based on the Nonspecific Esterase Technique}

After euthanasia of the animals, the surface portions of the sternomastoid muscles were trimmed to the middle third (containing the motor point), which was cut length wise into three or four slices. The resulting material was subjected to the nonspecific esterase reaction [47] to characterize the NMJ.

2.2.1.1. Morphometric Analysis. Maximum diameter measurements were performed on 50 junctions from a total of five animals from each experimental group (Control and Laser). The measures were analyzed with the help of Image J software (http://rsbweb.nih.gov/ij/).

2.2.2. Morphological Analysis of the NMJ by Transmission Electron Microscopy (TEM) and Morphology and Morphometry Analyses by Confocal Microscopy

After anesthesia and trichotomy, the skin in the pectoral region was dissected and the sternal plastron was folded down. The thoracic viscera were exposed, and perfusion was performed via the left ventricle. First, the animals were perfused with PBS, followed by fixation with $2.0 \%$ paraformaldehyde in $0.1 \mathrm{M}$ sodium phosphate buffer, $\mathrm{pH}$ 7.4. The caudal vena cava was sectioned near the right atrium to drain blood and excess liquid from the perfusion.

2.2.2.1. Transmission Electron Microscopy (TEM). The muscular portion containing the motor point was reduced into fragments, which were then immersed in Karnovsky fixative solution and subjected to the routine technique for TEM. The tissues were sliced so that longitudinal sections of muscles were obtained to allow identification of the NMJ. Ultrafine slices were obtained and examined, and the findings were documented using a Philips transmission electron microscope (model CM100 FEI).

2.2.2.2. Confocal Microscopy. The muscles were reduced in the region containing the motor point, fixed with $2 \%$ paraformaldehyde and subjected to a protocol to mark acetylcholine receptors and nerve terminals. The fragments were kept in fixative for $15 \mathrm{~min}$ and then washed with PBS three times for 5 min each to inactivate the fixative. Next, 
they were incubated with $0.1 \mathrm{M}$ glycine for $30 \mathrm{~min}$ on an orbital shaker and subsequently washed with PBS and incubated with $1 \%$ collagenase (Sigma Type I C-0130) for 30 min on the shaker to assist with connective tissue removal. Following this, they were washed with PBS, and the nAChRs were labeled with $\alpha$-bungarotoxin conjugated to rhodamine (Rh-BTX, Molecular Probes T1175, 1:1000 in PBS) for $40 \mathrm{~min}$ on the shaker. Then, the muscles were washed with PBS four times (for 5 min per wash) and incubated with 1\% Triton X-100 (Sigma T9284) for $1 \mathrm{~h}$ to permeabilize the muscle fibers. Subsequently, the samples were left overnight in blocking solution ( $60 \mu \mathrm{l}$ of Triton X-100, $0.3 \mathrm{~g}$ of $3 \%$ bovine serum albumin, $0.2 \mathrm{~g} 2 \%$ skimmed milk powder, $3.75 \mathrm{mg}$ glycine (1\%), $800 \mu \mathrm{l} 8 \%$ fetal bovine serum, diluted in $10 \mathrm{ml}$ PBS) on the shaker to block or decrease nonspecific binding of the primary antibody. After this period, the fragments were incubated with the primary antineurofilament antibody (Ab) (Anti-neurofilament 200, Sigma N-5389, $1 \mu \mathrm{l}: 1 \mathrm{ml}$ in blocking solution) at $4{ }^{\circ} \mathrm{C}$ for $12 \mathrm{~h}$. On the following day, they were washed with PBS (changed every $20 \mathrm{~min}$ for $1 \mathrm{~h}$ and $30 \mathrm{~min}$ ) and incubated with secondary anti-mouse-IgG-FITC (Sigma ${ }^{\circ}$ F-0257, $1 \mu \mathrm{l}: 1 \mathrm{ml}$ in blocking solution) for $3 \mathrm{~h}$ at $4{ }^{\circ} \mathrm{C}$ on the shaker. Then, the samples were washed again in PBS for $1 \mathrm{~h}$ and mounted on slides under a cover slip in Vectashield ${ }^{\circledR}$ mounting medium for fluorescence staining with DAPI (Vector Laboratories).

The images were acquired using a Laser Scanning Confocal Microscope (Leica TCS model - SP5) belonging to the Electron Microscopy Center of IBB/UNESP/Botucatu and were analyzed using Image J software (http://rsbweb.nih.gov/ij/).
Morphological analysis was performed on the nerve terminals and acetylcholine receptors, and morphometric analysis was performed on approximately 30 axon terminals from five animals from each experimental subgroup. Measurements were taken of the area, perimeter, largest orthogonal axis of each nAChR and relative planar area (area of the $n A C h R /$ largest orthogonal axis of each nAChR) [48].

\subsubsection{Western Blotting}

After euthanasia, samples from the middle third of the muscles were frozen and then homogenized in tissue homogenizer (IKA UltraTurrax/ T-25) with $0.5 \mathrm{ml}$ of lysis buffer ( $1 \%$ Triton X-100, $10 \mathrm{mM}$ sodium pyrophosphate, $100 \mathrm{mM}$ sodium fluoride, aprotinin, $10 \mu \mathrm{g} / \mathrm{ml}, 1 \mathrm{mM}$ PMSF,0.25 mM sodium orthovanadate $\left(\mathrm{Na}_{3} \mathrm{VO}_{4}\right), 150 \mathrm{mM} \mathrm{NaCl}$ and $50 \mathrm{mM}$ Tris- $\mathrm{HCl}$ at $\mathrm{pH}$ 7.5). The samples were centrifuged at $11,000 \mathrm{rpm}$ for $20 \mathrm{~min}$, and the supernatant was collected. One $100-\mu \mathrm{l}$ aliquot of the homogenate was treated with $100 \mu \mathrm{l}$ of Laemmli sample buffer (2\% SDS, 20\% glycerol, $0.04 \mathrm{mg} / \mathrm{ml}$ bromophenol blue, $0.12 \mathrm{M}$ Tris- $\mathrm{HCl}$ at $\mathrm{pH} 6.8$ and $0.28 \mathrm{M} \beta$-mercaptoethanol). The samples were then incubated at $97{ }^{\circ} \mathrm{C}$ for $5 \mathrm{~min}$ and stored in a freezer at $-20{ }^{\circ} \mathrm{C}$ until use.

One aliquot of the pure extract of each sample (not treated with Laemmli) was used to quantify the total protein by the Bradford method [49]. Exact quantities of the total protein in each sample (70 $\mu \mathrm{g})$ were subjected to electrophoresis in $4-15 \%$ polyacrylamide gels (SDSPAGE) and then transferred to nitrocellulose membranes (Bio-Rad Laboratories, Hercules, CA) in a humidified system. The proteins
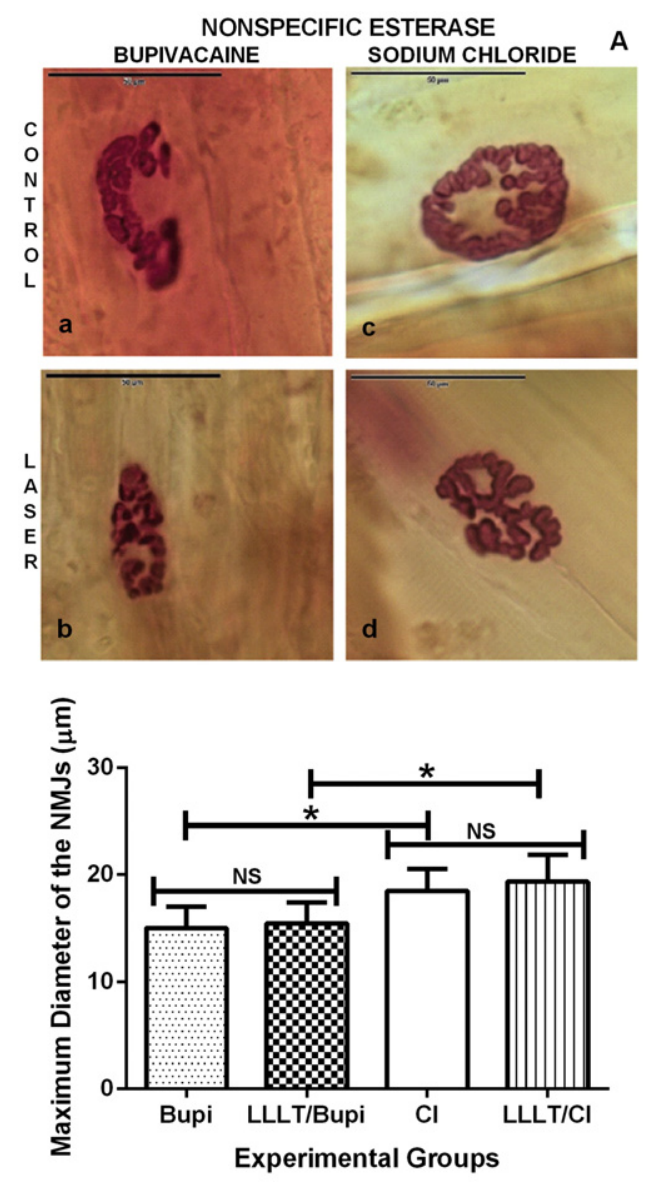

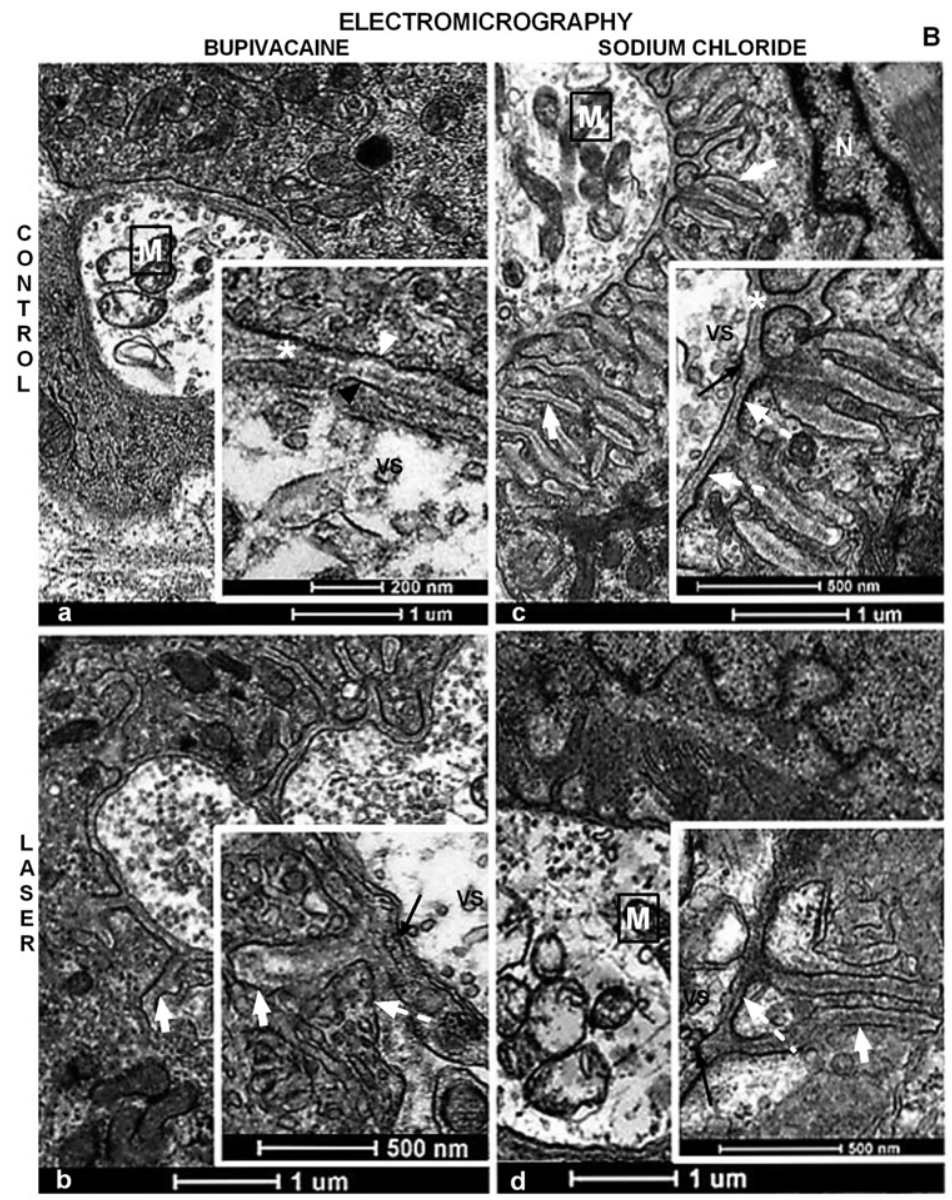

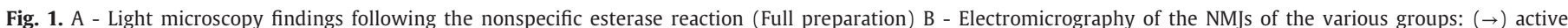

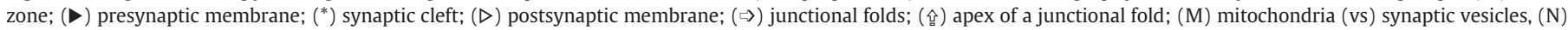

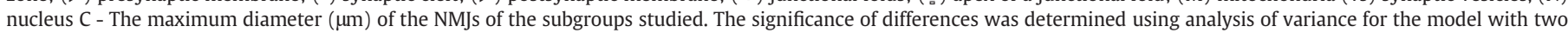
factors, together with the multiple comparison Tukey test, considering a 5\% level of significance, $\left({ }^{*}\right) p<0.05[50]$. 
transferred to membranes were blocked with 5\% skimmed milk diluted in TBS-Tween for $1 \mathrm{~h}$ at room temperature and incubated with different primary antibodies (AChR $\alpha 1$ (Santa Cruz Biotechnology - sc-136,130) 1:100; AChR $\gamma$ (Santa Cruz Biotechnology - sc-13,998) 1:150; AChRe (Santa Cruz Biotechnology- sc-13,999) 1:150; GAPDH (Cell Signaling 14C10)1:1000, overnight at $4{ }^{\circ} \mathrm{C}$. After incubation with primary antibodies, the membranes were washed in TBS-Tween and incubated with specific secondary antibodies (anti-rabbit (Cell Signaling - $7074 \mathrm{~s}$ ) 1:5000 or anti-mouse (Santa Cruz Biotechnology - sc-2005) 1:2000) for $1 \mathrm{~h}$ at room temperature. The membranes were washed again, and the ECL ${ }^{T M}$ Selected Western Blotting Detection Reagent (GE Healthcare, Uppsala, Sweden) was used. After image capture in a transilluminator $G$-Box, densitometric quantification of the bands was performed using Image J software (version 1.71, 2006, Austria). The protein expression values were normalized to the values obtained for the GAPDH protein, which were used as a reference.

\section{Results}

\subsection{Neuromuscular Junction: Morphology and Morphometry}

The nonspecific esterase technique allowed for visualization of the distribution of NMJs in the surface portion of the sternomastoid muscle. NMJs are characterized by a wide and highly branched synaptic gutter, with transverse striations corresponding to junctional folds (Fig. 1Ac). Some forms have fewer branches and small terminal projections. In this analysis, there were clear differences in the size and appearance of the NMJs in the $\mathrm{Cl}$ subgroup (Fig. 1Ac) compared to those in the Bupi subgroup (Fig. 1Aa). The $\mathrm{Cl}$ and LLLT/Cl subgroups presented greater complexity of the sites marked by the nonspecific esterase technique.

Morphometrically, there were no significant differences in the NMJs between the Bupi and LLLT/Bupi subgroups or between the Cl and LLLT/ $\mathrm{Cl}$ subgroups. However, the maximum diameters were smaller in the Bupi (15.048 \pm 1.985$)$ and LLLT/Bupi subgroups (15.456 \pm 1.983$)$ compared to the $\mathrm{Cl}(18.502 \pm 2.058)$ and LLLT/Cl subgroups (19.356 \pm 2.522) $(p<0.05)$ (Fig. 1C).

The ultrastructure of the neuromuscular junctions in the $\mathrm{CI}$ subgroup presented standard morphological characteristics, with several synaptic buttons, and were arranged in synaptic gutters with varied shapes and depths. Synaptic vesicles, mitochondria, and multivesicular bodies were present in the synaptic buttons. Characteristically, the presynaptic membrane presented more electron-dense regions corresponding to active zones, counter posed to the apex of the junctional folds of the postsynaptic membrane. The postsynaptic membrane was intact and contained numerous and long junctional folds, containing a more electron-dense apex corresponding to the local concentration of the acetylcholine receptors. These morphological patterns were also observed in the LLLT/Cl subgroup (Fig. 1B).

In the Bupi subgroup, the synaptic vesicles and other organelles present in the synaptic buttons exhibited different stages of degeneration, and it was not possible to identify the region of the active zones. Junctional folds were not evident in the postsynaptic membrane, and the electron density was observed along the entire length of the postsynaptic membrane. In the LLLT/Bupi subgroup, although signs of degeneration of the organelles of the synaptic buttons were still observed, junctional folds were present with electron dense areas along them, primarily at the apex.

The synaptic clefts in the groups studied presented no morphological changes and displayed a basal lamina with normal characteristics in the interior (Fig. 1B).

\subsection{Confocal Microscopy}

In the $\mathrm{CI}$ subgroup, the acetylcholine receptors and nerve terminals showed a normal distribution, where the responses of the fluorophores were homogeneous and the nAChRs had auto fluorescence.
The analysis revealed a large number of nuclei (blue) present in the laser group (Fig. 2A b and d) compared to the control group (Fig. 2A a and $\mathrm{c}$ ). With regard to the nerve terminals (green), no alterations were observed among the groups, and the nerve terminal were intact, preserved, and seamless in all subgroups.

In relation to the acetylcholine receptors (red), the chromogen dispersion was clear in the Bupi subgroup, demonstrating discontinuous marking. In the LLLT/Bupi subgroup, there was less dispersion of chromogen, and in the LLLT/Cl subgroup, there was greater complexity, with nAChR staining.

In the CI subgroup, the NMJs were characterized by the presence of continuous arms that ran in various directions along the muscle fibers. After application of laser therapy, the presence of larger and longer branches was observed in the LLLT/Cl subgroup.

Regarding the morphometry performed in the area of the nAChRs of the motor plate, the area in the $\mathrm{Cl}(759.43)$ and LLLT/Cl subgroups (803.70) was higher than that of the Bupi (76.30) and LLLT/Bupi subgroups (186.30) $(p<0.01)$ (Fig. 2B). This physiological response was also observed in the morphology of the perimeter. However, the LLLT/ Bupi subgroup (150.33) had significantly higher values compared to the Bupi subgroup (74.69) $(p<0.01)$. The relative planar area of the NMJ was significantly higher in the LLLT/Bupi subgroup (8.75) compared to the CBupi subgroup (4.80) $(p<0.01)$ (Fig. 2B).

The percentage of nerve terminals present in the experimental groups was not evaluated.

\subsection{Western Blotting}

The analysis of $n A C h R \alpha 1$ protein expression showed that the values were not significantly different between the control and laser groups, maintaining similar values in all experimental subgroups (Fig. 2E). There was a decrease in the protein expression of nAChR $\gamma$ in the LLLT/ $\mathrm{Cl}$ subgroup compared to the $\mathrm{CI}$ subgroup $(p<0.05)$ (Fig. 2D). There was no increase in the protein expression of nAChRe in the LBI/Bupi subgroup compared to the Bupi subgroup $(p<0.01)$. However, in the LLLT/CI subgroup, the values were lower compared to those in the LLLT/Bupi subgroup $(p<0.01)$ (Fig. 2C).

When all of the experimental groups were considered together (control and laser) for all nAChR subunits, there was a positive association of subunits $\alpha$ and $\gamma(p<0.05)$. It was not possible to demonstrate significance when the groups were considered separately; however, it is clear that the association remained positive in the laser group (high values in both the $\alpha$ and $\gamma$ subunits). The control group showed a negative relationship (high values for subunit $\gamma$ occurring in conjunction with low values for subunit $\alpha$ and vice versa). In summary, there was a direct relationship between subunits $\alpha$ and $\gamma$ in the laser group, and the reverse relationship was found for the control group (Fig. 3).

\section{Discussion}

The aim of this study was to investigate the effects of LLLT on the morphology of the NMJ and nAChRs after the induction of myonecrosis by the local anesthetic bupivacaine. The results point to a positive effect of laser therapy on the structural recovery of the NMJs and molecular recovery of nAChRs.

Based on the morphometry of the NMJs determined by the nonspecific esterase technique, there was a clear decrease in the maximum diameter of NMJs associated with the muscles injected with bupivacaine. Ultrastructurally, signs of degeneration were present in the pre- and postsynaptic regions, with characterization of the active zone and loss of junctional folds in the Bupi subgroup. Disaggregation of nAChRs was detected by confocal microscopy.

Significant changes in the ultrastructural architecture of the NMJs was also observed $4 \mathrm{~h}$ after bupivacaine injection, with an increase in the space of the synaptic cleft, loss of junctional folds, and discontinuity or absence of post-junctional plasmatic membranes [28]. Disaggregation 

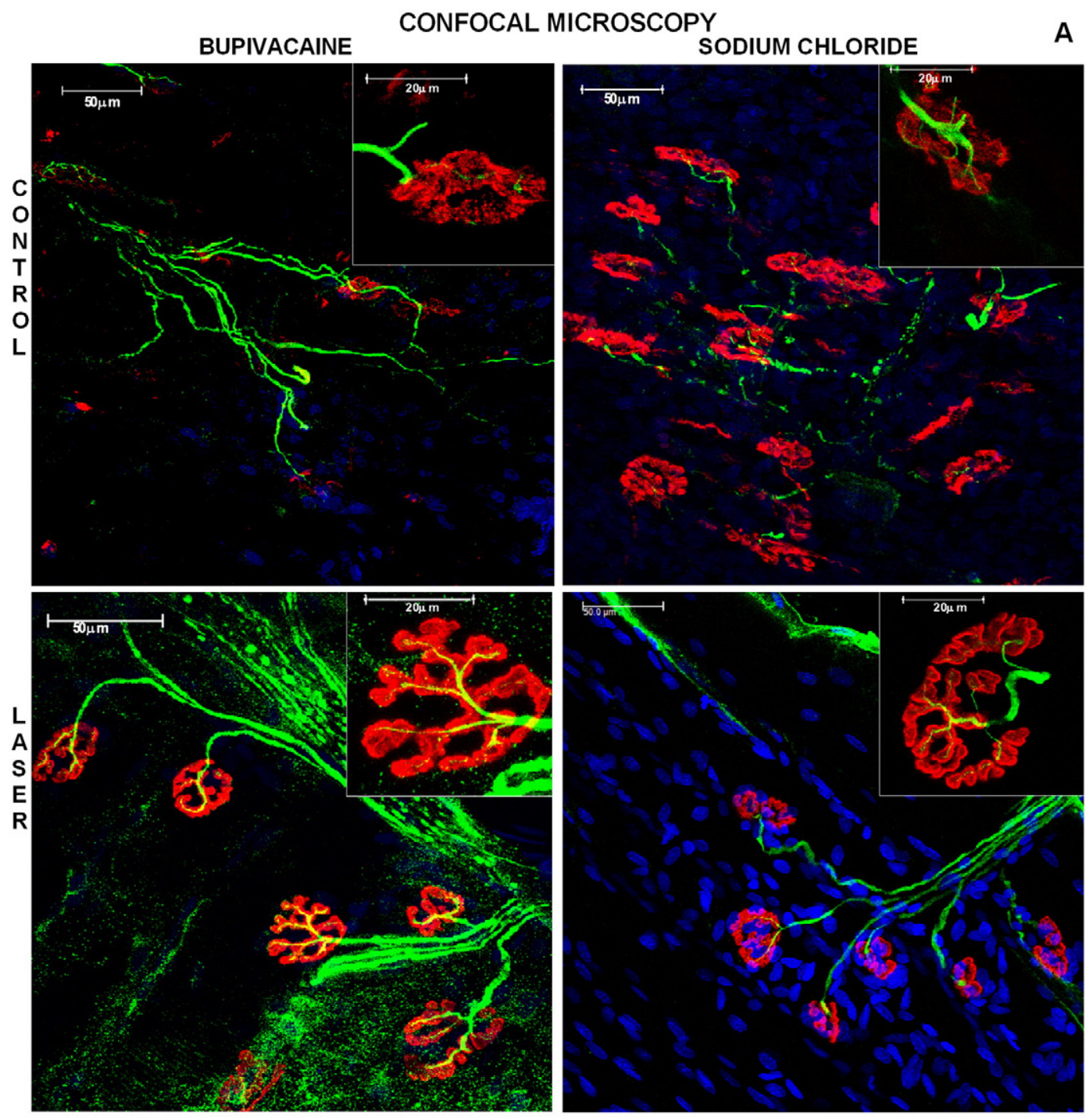

A

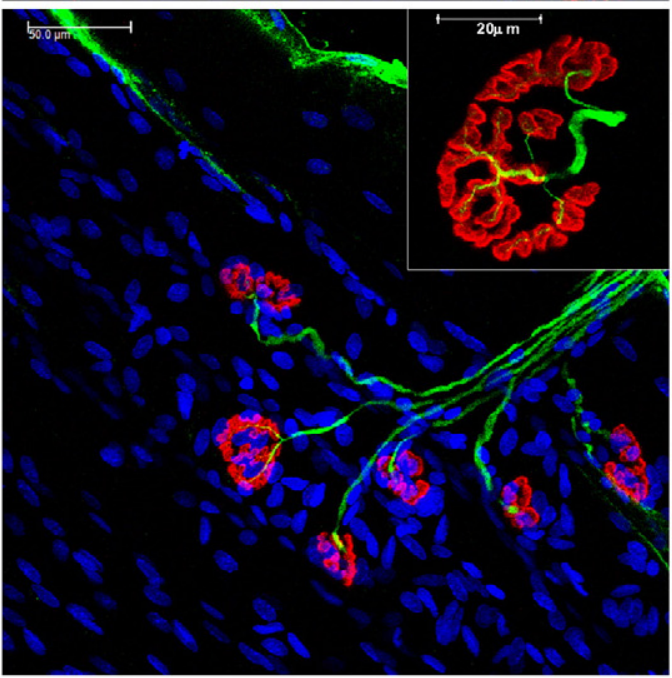

B

C

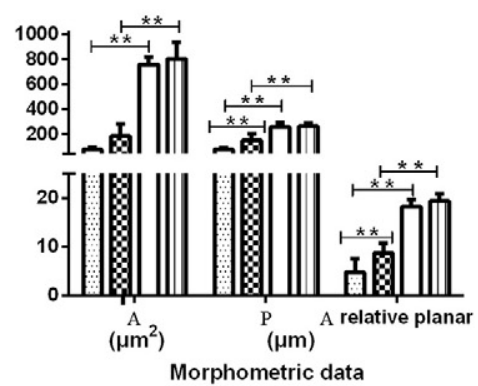

Bupi

$\infty$ LLLT/Bupi

$\square \mathrm{Cl}$

미 LLTC
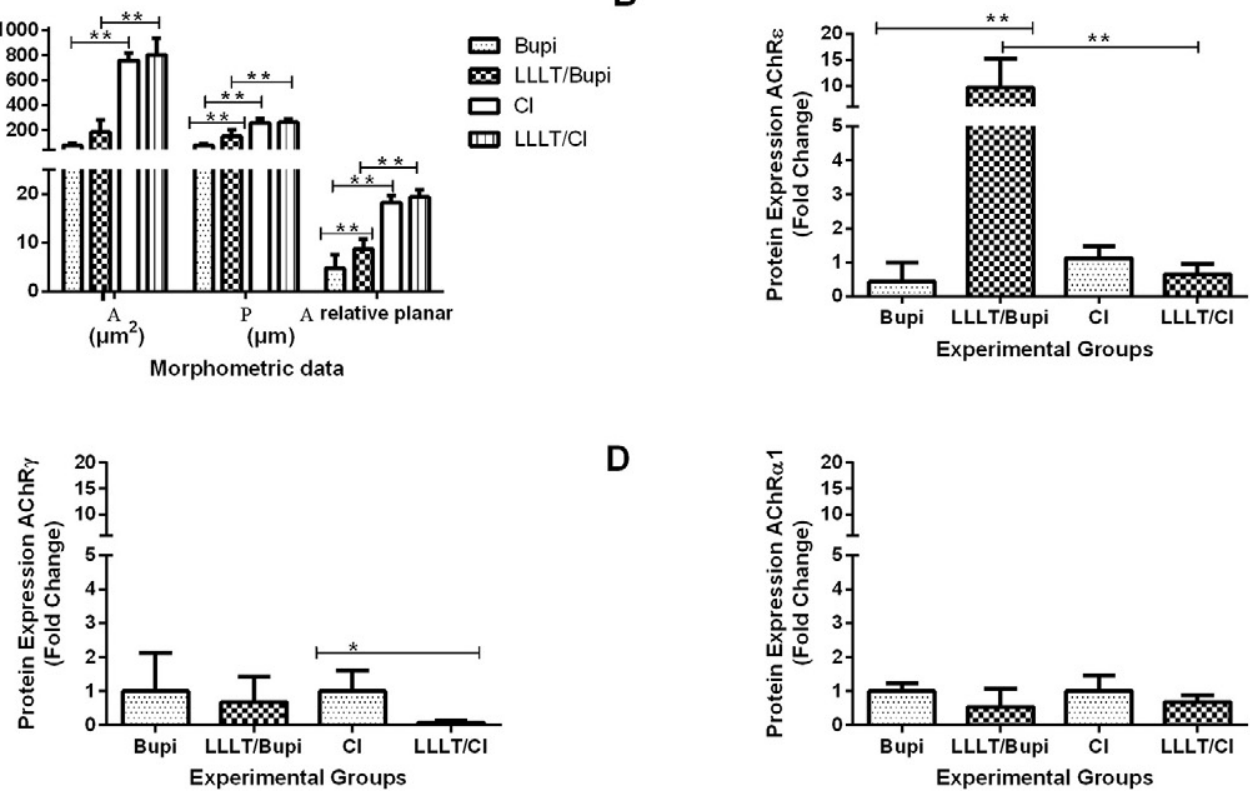

D

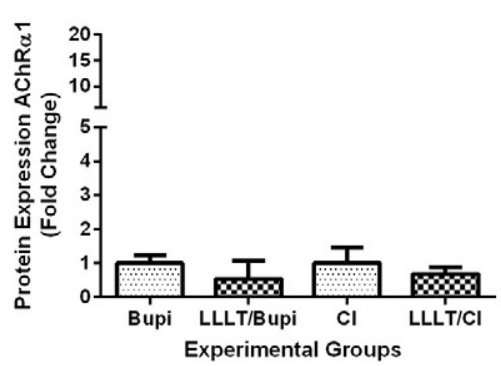


of the nAChR (an "islands" pattern) was present in the regenerated fibers of mdx mice [24,52].

In a study on the effects of another local anesthetic, lidocaine, the authors observed the same morphology 21 days after application of the anesthetic [23]. A similar alteration was observed in mdx mice, which was described how a secondary consequence of the regeneration of muscle fibers and not the absence of dystrophin [24].

This postsynaptic disaggregation in the Bupi subgroup was not accompanied by alterations in protein expression of the $\gamma$ or $\alpha 1$ receptors, but there was a decrease in the expression of the nAChRE subunit. A decrease in this subunit has been associated with structural destabilization of the NMJ. Severe muscle weakness and premature death were observed in experimental animals in the absence or deficiency of nAChRe [25]. A decrease in the gene expression of the epsilon subunit has been associated with a loss in ERK2 (extracellular signal-regulated kinase), which is involved in the activation of agrin, a key synaptogenic factor involved in the formation and maintenance of the NMJ [53]. Furthermore, the area, perimeter, and relative planer area determined by confocal microscopy were smaller in the Bupi subgroup. These data are consistent with the degenerative effects of the local anesthetic on NMJs.

Regarding the nerve terminals (green chromogen), no significant alterations were evident in relation to the experimental group, with all groups showing whole and preserved nerve terminals, without signs of discontinuity. Although confocal microscopy was not used in their studies, some researchers have been evaluated the nerve terminals after the application of bupivacaine and did not observe any alterations [27-29].

It is possible that the myonecrosis arising from bupivacaine promotes sarcolemmal injury, allowing excessive entry of calcium. This ion leads to hypercontraction of myofibrils [27,54,55], increasing the quantity of intracellular free radicals due to the generation of oxidative stress, culminating in mitochondrial degeneration [39]. Considering that proteins in the synaptic region are transmembranic, alterations in the plasma membrane of the fiber and its sarcoplasm directly affect the muscle synapse [21], such that alterations in the NMJs can be considered responses to the pathological process of myonecrosis [29].

After LLLT application, there was an increase in the relative planar area of the NMJ. Considering that this measurement refers to the degree of branching and fragmentation of the NMJ, indicating its complexity index, it is clear that there was recovery in the NMJ after LLLT, due to the fact that a higher relative planar area indicates lower fragmentation of the NMJ, and vice versa [48].

There was also a clear approximation of the ultrastructural morphological aspect of the NMJ in the LLLT/CI and LBI/Bupi groups, with the active zones showing a clear orientation of synaptic vesicles and increase in the number of junctional folds. A loss or reduction of the number of junctional folds is characteristic of degenerate fibers, demonstrating that muscle regeneration leads to remodeling of pre- and postsynaptic components [23,56].

Even in the initial stages of regeneration, the active zone is present in specific regions of the presynaptic membrane as opposed to the junctional folds. The active zone is a neurotransmitter release site and is disorganized during the regeneration process, facilitating exocytosis from synaptic vesicles, releasing neurotransmitters [57].

Changes in junctional folds can lead to a loss of nAChRs and remodeling of the NMJ [58]. The efficiency of electrical transmission is enhanced by the formulation of the junctional folds and by the expression of adult AChRs and voltage-dependent sodium channels
[59]. Regeneration of the NMJ follows the steps of myogenesis, with the process including the formation of new junctional folds [28].

In our confocal microscopy study, a lower dispersion of nAChRs (red chromogens) was evident in the groups that received LLLT, suggesting that there was a stabilization of nAChRs. The stabilization of nAChRs is dependent on the calcium influx during electrical activity [60-61].

After laser therapy, there was also a significant increase in protein expression of the $\varepsilon$ receptor. The $\varepsilon$ subunit is associated with a small opening of nAChR ion channels, regulating the influx of calcium, thus ensuring the stabilization of the initial interaction between nerve and muscle and synaptic maturation [25,62-63]. It is an essential subunit that is required for the maintenance of the organization and protection of the synaptic region against adverse effects resulting from excessive intake of calcium in adult muscle tissue [25,63].

When the subgroups are considered together, there was a strong positive association between the $\alpha 1$ and $\gamma$ subunits. However, the $\alpha$ and $\gamma$ subunits are regulated independently, and an increase in the $\alpha 1$ subunit is not directly associated with alterations in the $\gamma$ and $\varepsilon$ subunits [25].

In experiments in which subunit $\gamma$ was replaced by a subunit with similar functional properties to the $\varepsilon$ subunit, a pattern of altered muscle innervation was present, suggesting that during muscle development, nAChR $\gamma$ ensures an orderly innervation pattern for skeletal muscle [64]. The expression of fetal nAChR is crucial to maintain the neuromuscular transmission in individuals with deficiencies caused by alterations in the nAChRe subunit and is associated with upregulation of the mRNA expression of the $\gamma$ subunit [25].

The use of LLLT increases neovascularization [65] and the expression of growth factors [66] and decreases oxidative stress, inflammation [67] and myonecrosis, activating precursor cells of myogenesis (satellite cells) [32]. Studies involving muscle regeneration of elderly rats undergoing laser therapy showed an increase in the maturation of satellite cells into myoblasts and myotubes [68]. In the same way, the confocal microscopy experiment in the present study revealed a large number of nuclei (blue) in the group that received laser therapy. The marker used for the nucleus was not able to differentiate among cells, so the nuclei may have corresponded to inflammatory cells and muscle fibers or may have even indicated an increased number of satellite cells.

Considering that the muscle regeneration capacity primarily depends on the survival of satellite cells [69], it is well established that these cells are resistant to local anesthetics [70]. In addition, following injury, the muscles and NMJs pass through a regeneration process, which is partly regulated by myogenic regulatory factors (MRFs) [71]. MRFs are also targets of the laser, which promotes muscle regeneration [72], accelerating the processes of proliferation and differentiation [32, 66].

During the remodeling of denervated/regenerated fibers, type IV collagen and non-neural agrin contribute to a new conformation of the pre- and postsynaptic components. This new distribution follows a pretzel or continuous arm pattern that is characteristic of the adult NMJ (mature). Therefore, the nerve terminal influences the spatial organization of the nAChRs. Thus, it can be inferred that changes in the distribution pattern of nAChRs are part of the processes of degeneration and regeneration of the muscle fiber [73].

It is well established that the mitochondrial electron transport chain is photosensitive to red and infrared light, and when activated by LLLT, there is an increase in the space between the inner and outer membranes of the mitochondria, which dilates the mitochondrial crest [74]. Exposure to laser light also increases the synthesis of adenosine triphosphate (ATP) and $\mathrm{O}_{2}$ consumption [41].

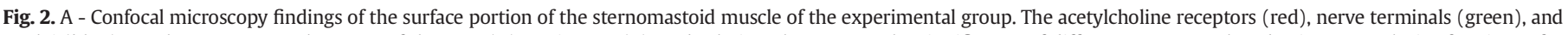

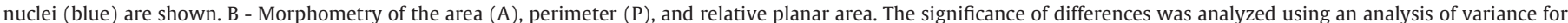

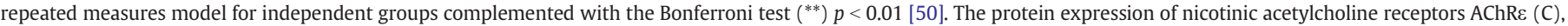

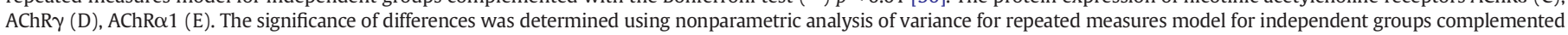
with the Dunn test [50]. $\left(^{*}\right) p<0.05$, and $\left(^{* *}\right) p<0.01$. 
Receptors dispe rsion diagram

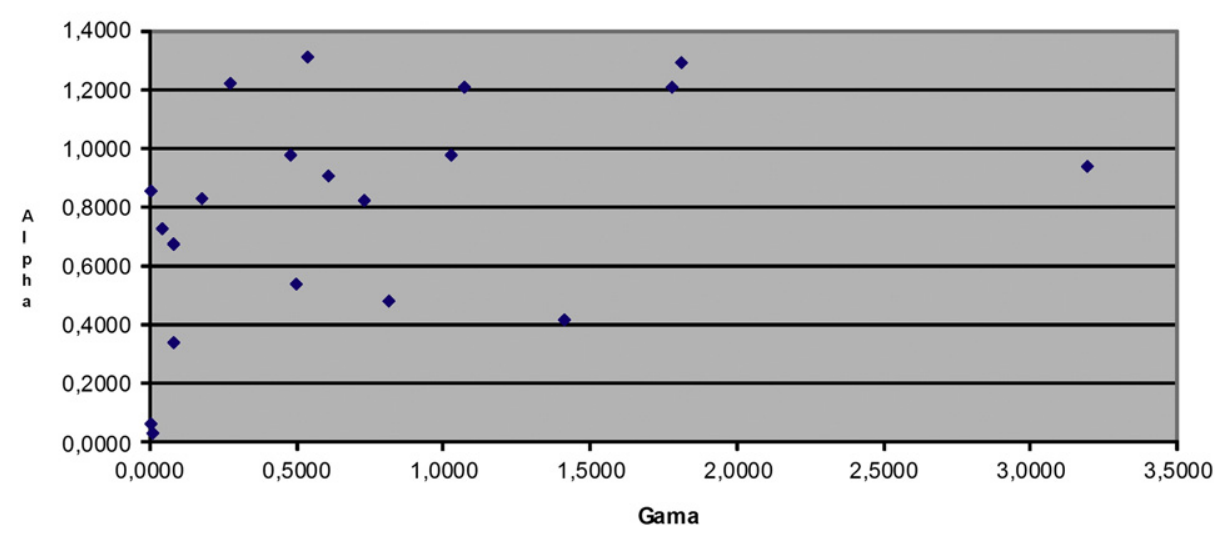

Fig. 3. Dispersion data for the $\alpha$ and $\gamma$ subunits of the nAChRs. The data were analyzed using the Spearman correlation [51].

Cytochrome $c$ oxidase (complex IV of the mitochondrial respiratory chain) is a key light photoreceptor with a near-infrared spectral range. After application of laser therapy with GaAs $(904 \mathrm{~nm})$, the activity levels of complexes I, II, III and IV of the mitochondrial respiratory chain were increased in the injured muscle [75].

Biostimulation produces primary effects during cell proliferation in the muscle healing process. At the cellular level, low power photo-irradiation promotes significant biological effects, such as stimulation of macrophages and lymphocytes and release of growth factors from cells [76].

The presence of myopathy induced by bupivacaine used for nerve blocks and other local anesthetic injections has been increasingly described $[43,77-78]$. However, the available literature suggests that the myotoxicity that developed after local anesthetic use is subclinical and reversible, most likely due to the short exposure time [77-81]. Continuous infusion pumps are now being used for pain, and it is still unknown whether local anesthetics may cause more significant (i.e., irreversible) muscle injury in these individuals due to the prolonged exposure time [82].

\section{Conclusion}

Considering that LLLT in the dose used in the present study reduced the structural alterations of the NMJ and molecular alterations of nAChRs triggered by bupivacaine, this approach appears to represent a therapeutic protocol that may be indicated after injuries triggered by exposure to local anesthetics. Further studies should be conducted to fully clarify the mechanism(s) of action.

\section{Competing Interests}

The authors declare no competing interests.

\section{Research Support}

This work was supported by FAPESP Grant n 13/26649-3.

\section{References}

[1] J.C.A. Carvalho, Farmacologia dos anestésicos locais, Rev. Bras. Anestesiol. 44 (1) (1994) 75-82.

[2] H.R. Arias, Role of local anesthetics on both cholinergic and serotonergic ionotropic receptors, Neurosci. Biobehav. Rev. 23 (6) (1999) 817-843.

[3] A. Kojima, J.Y. Bai, Y. Ito, W.G. Ding, H. Kitagawa, H. Matsuura, Serum albumin attenuates the open-channel blocking effects of propofol on the human Kv1.5 channel, Eur. J. Pharmacol. (2016 May 6) (pii: S0014-2999(16)30314-4).

[4] B. Cobb, Y. Cho, G. Hilton, V. Ting, B. Carvalho, Active warming utilizing combined IV fluid and forced-air warming decreases hypothermia and improves maternal comfort during cesarean delivery: a randomized control trial, Anesth. Analg. 122 (5) (2016 May) 1490-1497.

[5] N. Kishore, Y.S. Payal, N. Kumar, N. Chauhan, In spinal anaesthesia for cesarean section the temperature of bupivacaine affects the onset of shivering but not the incidence: a randomized control trial, J. Clin. Diagn. Res. 10 (1) (2016 Jan) UC18-UC21.

[6] I. Balga, H. Gerber, X.H. Schorno, F. Aebersold Keller, H.P. Oehen, Bupivacaine crystal deposits after long-term epidural infusion, Anaesthesist 62 (7) (2013 Jul) 543-548.

[7] B.J. Horn, A. Cien, N.P. Reeves, P. Pathak, C.J. Taunt Jr., Femoral nerve block vs Periarticular bupivacaine liposome injection after primary Total knee Arthroplasty: effect on patient outcomes, J. Am. Osteopath. Assoc. 115 (12) (2015 Dec 1) 714-719.

[8] V.V. Jaichandran, R. Raman, L. Gella, T. Sharma, Local anesthetic agents for vitreoretinal surgery: no advantage to mixing solutions, Ophthalmology 122 (5) (2015 May) 1030-1033.

[9] B.M. Ilfeld, E.R. Viscusi, A. Hadzic, H.S. Minkowitz, M.D. Morren, J. Lookabaugh, G.P. Joshi, Safety and side effect profile of liposome bupivacaine (Exparel) in peripheral nerve blocks, Reg. Anesth. Pain Med. 40 (5) (2015 Sep-Oct) 572-582.

[10] P. Shapiro, H. Schroeck, Seizure after abdominal surgery in an infant receiving a standard-dose postoperative epidural BupivacaineInfusion, AA Case Rep. 28 (2016 Jan).

[11] K. Nouette-Gaulain, C. Jose, X. Capdevila, R. Rossignol, From analgesia to myopathy: when local anesthetics impair the mitochondrion, Int. J. Biochem. Cell Biol. 43 (1) (2011 Jan) 14-19.

[12] Reza-Fazel M. Abdolhossein-Davoodabadi, H. Reza-Vafaei, S. Parviz, Comparison of the effects of intrapleural bupivacaine and morphine on post-thoracotomy pain, Middle East J. Anaesthesiol. 23 (3) (2015 Oct) 267-272.

[13] H.C. Yang, J.Y. Lee, S. Ahn, S. Cho, K. Kim, S. Jheon, J.S. Kim, Pain control of thoracoscopic major pulmonary resection: is pre-emptive local bupivacaine injection able to replace the intravenous patient controlled analgesia? J. Thorac. Dis. 7 (11) (2015 Nov) 1960-1969.

[14] D.E. Beck, D.A. Margolin, S.F. Babin, C.T. Russo, Benefits of a multimodal regimen for postsurgical pain management in colorectal surgery, Ochsner J. 15 (4) (2015 Winter) 408-412.

[15] K.S. Kalchofner Guerrero, I. Campagna, R. Bruhl-Day, C. Hegamin-Younger, T.G. Guerrero, Intraperitoneal bupivacaine with or without incisional bupivacaine for postoperative analgesia in dogs undergoing ovariohysterectomy, Vet. Anaesth. Analg. 43 (5) (2016 Sep) 571-578.

[16] S.W. Yu, A.L. Szulc, S.L. Walton, R.I. Davidovitch, J.A. Bosco, R. Iorio, Liposomal bupivacaine as an adjunct to postoperative pain control in total hip arthroplasty, J. Arthroplast. (2016 Jan 21) (pii: S0883-5403(16)00064-4).

[17] L.F. Fraceto, S. Oyama Jr., C.R. Nakaie, A. Spisni, E. de Paula, T.A. Pertinhez, Interaction of local anesthetics with a peptide encompassing the IV/S4-S5 linker of the Na+ channel, Biophys. Chem. 123 (1) (2006 Aug 20) 29-39.

[18] C.L. Gentry, R.J. Lukas, Local anesthetics noncompetitively inhibit function of four distinct nicotinic acetylcholine receptor subtypes, J. Pharmacol. Exp. Ther. 299 (3) (2001 Dec) 1038-1048.

[19] A.C. Rossman, The physiology of the nicotinic acetylcholine receptor and its importance in the administration of anesthesia, AANA J. 79 (5) (2011 Oct) 433-440.

[20] Goodman \& Gilman, As Bases Farmacológicas da Terapêutica, 12 ed McGrallHill, 2012 757-769.

[21] Z. S. Wu, H. Cheng Y. Jiang K. Melcher, H.E. Xu, Ion channels gated by acetylcholine and serotonin: structures, biology, and drug discovery, Acta Pharmacol. Sin. 36 (8) (2015 Aug) 895-907, http://dx.doi.org/10.1038/aps.2015.66.

[22] N. Unwin, Nicotinic acetylcholine receptor and the structural basis of neuromuscular transmission: insights from Torpedo postsynaptic membranes, Q. Rev. Biophys. 46 (4) (2013 Nov) 283-322.

[23] E. Minatel, H. Santo Neto, M.J. Marques, Acetylcholine receptors and neuronal nitric oxide synthase distribution at the neuromuscular junction of regenerated muscle fibers, Muscle Nerve 24 (3) (2001 Mar) 410-416.

[24] M.J. Marques, Z.T. Mendes, E. Minatel, Neto H. Santo, Acetylcholine receptors and nerve terminal distribution at the neuromuscular junction of long-term regenerated muscle fibers, J. Neurocytol. 34 (6) (2005 Dec) 387-396. 
[25] D. Kalamida, K. Poulas, V. Avramopoulou, E. Fostieri, G. Lagoumintzis, K. Lazaridis, A. Sideri, M. Zouridakis, S.J. Tzartos, Muscle and neuronal nicotinic acetylcoline receptors. Structure, function and pathogenicity, FEBS J. 274 (15) (2007 Aug) 3799-3845

[26] R. Mantegazza, C. Cordiglieri, A. Consonni, F. Baggi, Animal models of myasthenia gravis: utility and limitations, Int. J. Gen. Med. 9 (2016 Mar 4) 53-64.

[27] P.W. Benoit, W.D. Belt, Destruction and regeneration of skeletal muscle after treatment with a local anesthetic, bupivacaine (Marcaine), J. Anat. 107 (1970) 547-556.

[28] T. Nishizawa, H. Tamaki, N. Kasuga, H. Takekura, Degeneration and regeneration of neuromuscular junction architecture in rat skeletal muscle fibers damaged bybupivacaine hydrochloride, J. Muscle Res. Cell Motil. 24 (8) (2003) 527-537.

[29] M. Sadeh, L.Z. Stern, K. Czyzewski, Changes in end-plate cholinesterase and axons during muscle degeneration and regeneration, J. Anat. 140 (Pt 1) (1985 Jan) $165-176$.

[30] A. Brugnera-Jr, A.L.B. Pinheiro, Lasers na odontologia moderna, São Paulo, Pancast, 1998.

[31] C. Ferraresi, M.R. Hamblin, N.A. Parizotto, Low-level laser (light) therapy (LLLT) on muscle tissue: performance, fatigue and repair benefited by the power of light, Photonics Lasers Med. 1 (4) (2012 Nov 1) 267-286.

[32] A.N. Alves, K.P. Fernandes, A.M. Deana, S.K. Bussadori, R.A. Mesquita-Ferrari, Effects of low-level laser therapy on skeletal muscle repair: a systematic review, Am. J. Phys. Med. Rehabil. 93 (12) (2014 Dec) 1073-1085

[33] W.J. Genovese, Laser de baixa intensidade: aplicações terapêuticas em odontologia, São Paulo, Ed. Santos, 2007.

[34] A.N. Alves, K.P.S. Fernandes, C.A.V. Melo, R.Y. Yamaguchi, C.M. França, D.F. Teixeira, S.K. Bussadori, F.D. Nunes, R.A. Mesquita-Ferrari, Modulating effect of low levellaser therapy on fibrosis in the repair process of the tibialis anterior muscle in rats, Lasers Med. Sci. 29 (2) (2014 Mar) 813-821.

[35] C.E.A. Freitas, R.S. Bertaglia, I.J.V. Junior, E.A. Mareco, R.A.S. Salomão, T.G. de Paula, G.A. Nai, R.F. Carvalho, F.L. Pacagnelli, M. Dal-Pai-Silva, High final energy of low-level gallium arsenide laser therapy enhances skeletal muscle recovery without a positive effect on collagen remodeling, Photochem. Photobiol. 91 (2015) 957-965.

[36] A.M. Zagatto, Ramos S. de Paula, F.Y. Nakamura, F.S. de Lira, R.Á. Lopes-Martins, R.L de Paiva Carvalho, Effects of low-level laser therapy on performance, inflammatory markers, and muscle damage in young waterpolo athletes: a double-blind randomized, placebo-controlled study, Lasers Med. Sci. 31 (3) (2016 Apr) 511-521.

[37] R.A. Nicolau, M.S. Martinez, J. Rigau, J. Tomàs, Effect of low power 655 nm diode laser irradiation on the neuromuscular junctions of the mouse diaphragm, Lasers Surg. Med. 34 (3) (2004) 277-284.

[38] S. Rochkind, A. Shainberg, Protective effect of laser phototherapy on acetylcholine receptors and creatine kinase activity in denervated muscle, Photomed. Laser Surg. 31 (10) (2013 Oct) 499-504.

[39] O. Cela, C. Piccoli, R. Scrima, G. Quarato, A. Marolla, G. Cinnella, M. Dambrosio, N. Capitanio, Bupivacaine unclouples the mitochoncrial oxidative phosphorylation, inhibits respiratory chain complexes I and III enhances ROS production: results of a study on cell cultures, Mitochondrion 10 (5) (2010 Aug) 487-496.

[40] H. Chung, T. Dai, S.K. Sharma, Y.Y. Huang, J.D. Carroll, M.R. Hamblin, The nuts and bolts of low-level laser (light) therapy, Ann. Biomed. Eng. 40 (2) (2012 Feb) 516-533.

[41] T. Karu, Primary and secondary mechanisms of action of visible to near-IR radiation on cells, J. Photochem. Photobiol. B 49 (1) (1999 Mar) 1-17.

[42] C. Ferraresi, R.V. Dos Santos, G. Marques, M. Zangrande, R. Leonaldo, M.R. Hamblin, V.S. Bagnato, N.A. Parizotto, Light-emitting diode therapy (LEDT) before matches prevents increase in creatine kinase with a light dose response in volleyball players, Lasers Med. Sci. 30 (4) (2015 May) 1281-1287.

[43] C. Zhang, P. Phamonvaechavan, A. Rajan, D.Y. Poon, P. Topcu-Yilmaz, D.L. Guyton, Concentration-dependent bupivacaine myotoxicity in rabbit extraocular muscle, J AAPOS 14 (4) (2010 Aug) 323-327.

[44] D. Danieli-Betto, S. Peron, E. Germinario, M. Zanin, G. Sorci, S. Franzoso, D. Sandonà R. Betto, Sphingosine 1-phosphate signaling is involved in skeletal muscle regeneration, Am. J. Phys. Cell Physiol. 298 (3) (2010 Mar) C550-C558.

[45] X. Wen, S. Xu, H. Liu, Q. Zhang, H. Liang, C. Yang, H. Wang, Neurotoxicity induced by bupivacaine via T-type calcium channels in SH-SY5Y cells, PLoS One 8 (5) (2013 May 2), e62942.

[46] I. Otrocka-Domagała, A. Mikołajczyk, K. Paździor-Czapula, M. Gesek, T. Rotkiewicz, M. Mikiewicz, Effect of low-energy laser irradiation and antioxidant supplementation on cell apoptosis during skeletal muscle post-injury regeneration in pigs, Pol. J. Vet. Sci. 18 (3) (2015) 523-531.

[47] G.M. Lehrer, L. Ornstein, A diazo coupling method for the electron microscopic localization of cholinesterase, J. Biophys. Biochem. Cytol. 6 (1959 Dec) 399-406.

[48] D.C. Sieck, W.Z Zhan, Y.H. Fang L.G. Ermilov, G.C. Sieck, C.B. Mantilla, Structure-activity relationships in rodent diaphragm muscle fibers vs. neuromuscular junctions, Respir. Physiol. Neurobiol. 180 (1) (2012 Jan 15) 88-96.

[49] M.M. Bradford, A rapid and sensitive method for the quantitation of microgram quantities of protein utilizing the principle of protein-dye binding, Anal. Biochem. 72 (1976 May 7) 248-254.

[50] J.H. Zar, Biostatistical Analysis, 5ª̣ ed. Prentice-Hall, New Jersey, 2009994.

[51] G.R. Norman, D.L. Streiner, Biostatistics. The Bare Essentials. 3rd Ed, People's Medica Publishing House, Shelton, Connecticut, 2008.

[52] M.J. Marques, J.A. Conchello, J.W. Lichtman, From plaque to pretzel: fold formation and acetylcholine receptor loss at the developing neuromuscular junction, J. Neurosci. 20 (2000) 3663-3671.

[53] B. Seaberg, G. Henslee, S. Wang, X. Paez-Colasante, G.E. Landreth, M. Rimer, Musclederived extracellular signal-regulated kinases 1 and 2 are required for the maintenance of adult myofibers and their neuromuscular junctions, Mol. Cell. Biol. 35 (7) (2015 Apr) 1238-1253.
[54] D.E. Di Croce, P.W. Trinks, C. de La Cal, G.A. Sánchez, D. Takara, Amide-type local anesthetics action on the sarcoplasmic reticulum Ca-ATPase from fast-twitch skeletal muscle, Naunyn Schmiedeberg's Arch. Pharmacol. 387 (9) (2014 Sep) 873-881.

[55] C. Plank, P. Hofmann, M. Gruber, G. Bollwein, B.M. Graf, W. Zink, T. Metterlein, Modification of bupivacaine-induced myotoxicity with Dantrolene and caffeine in vitro, Anesth. Analg. 122 (2) (2016 Feb) 418-423.

[56] P.R. Lyons, C.R. Slater, Structure and function of the neuromuscular junction in young adult mdx mice, J. Neurocytol. 20 (12) (1991 Dec) 969-981.

[57] J.A. Szule, J.H. Jung, U.J. McMahan, The structure and function of active zone material' at synapses, Philos. Trans. R. Soc. Lond. Ser. B Biol. Sci. 5 (2015 Jul) 370(1672).

[58] B.A. Hesser, O. Henschel, V. Witzemann, Synapse disassembly and formation of new synapses in postnatal muscle upon conditional inactivation of MuSK, Mol. Cell. Neurosci. 31 (3) (2006 Mar) 470-480.

[59] S.J. Wood, C.R. Slater, Safety factor at the neuromuscular junction, Prog. Neurobiol. 64 (4) (2001 Jul) 393-429.

[60] S. Roztler, H.R. Brenner, Metabolic stabilization of acetylcholine receptors in vertebrate neuromuscular junction by muscle activity, J. Cell Biol. 111 (1990) 655-661.

[61] J.A. Powell, J. Molgó, D.S. Adams, C. Colasante, A. Williams, M. Bohlen, E. Jaimovich, IP3 receptors and associated $\mathrm{Ca}^{2+}$ signals localize to satellite cells and to components of the neuromuscularjun ction in skeletal muscle, J. Neurosci. 23 (23) (2003 Sep 10) 8185-8192.

[62] N. Yumoto, S. Wakatsuki, A. Sehara-Fujisawa, The acetylcholine receptor gamma-toepsilon switch occurs in individual endplates, Biochem. Biophys. Res. Commun. 331 (4) (2005 Jun 17) 1522-1527.

[63] A. Di Castro, K. Martinello, F. Grassi, F. Eusebi, A.G. Engel, Pathogenic point mutations in a transmembrane domain of the epsilon subunit increase the Ca2 + permeability of the human endplate ACh receptor, J. Physiol. 579 (Pt 3) (2007 Mar 15) 671-677.

[64] S. Gattenlöhner, C. Schneider, C. Thamer, R. Klein, W. Roggendorf, F. Gohlke, C. Niethammer, S. Czub, A. Vincent, H.K. Müller-hermelink, et al., Expression of foetal type acetylcholine receptor to type I muscle fibres in human neuromuscular disorders, Brain 125 (2000) 1309-1319.

[65] F.J. Dias, J.P.M. Issa, A.P.A. Barbosa, P.B. Vasconcelos, L. Watanabe, M. Mizusakilyomasa, Effects of low-level laser irradiation in ultrastructural morphology, and immunoexpression of VEGF and VEGFR-2 of rat masseter muscle, Micron 43 (2012) 237-244.

[66] J. Nakano, H. Kataoka, J. Sakamoto, T. Origuchi, M. Okita, T. Oshimura, Low-level laser irradiation promotes the recovery of atrophied gastrocnemius skeletal muscle in rats, Exp. Physiol. 94 (9) (2009 Sep) 1005-1015.

[67] A.B. Macedo, L.H. Moraes, D.S. Mizobuti, A.R. Fogaça, S. Moraes Fdos, A. Hermes Tde, A. Pertille, E. Minatel, Low-level laser therapy (LLLT) in dystrophin-deficient muscle cells: effects on regeneration capacity, inflammation response and oxidative stress, PLoS One 10 (6) (2015 Jun 17), e0128567.

[68] F. Vatansever, N.C. Rodrigues, L.L. Assis, S.S. Peviani, J.L. Durigan, M.A. Moreira Fernando, M.R. Hamblin, N.A. Parizotto, Low intensity laser therapy accelerates muscle regeneration in aged rats, Photonics Lasers Med. 1 (4) (2012) 287-297.

[69] B.M. Carlson, J.A. Faulkner, The regeneration of skeletal muscle fibers following injury: a review, Med. Sci. Sports Exerc. 15 (3) (1983) 187-198.

[70] I. Nonaka, A. Takagi, S. Ishiura, H. Nakase, H. Sugita, Pathophysiology of muscle fiber necrosis induced by bupivacaine hydrochloride (Marcaine), Acta Neuropathol. 60 (3-4) (1983) 167-174.

[71] T. Launay, A.S. Armand, F. Charbonnier, J.C. Mira, E. Donsez, C.L. Gallien, C. Chanoine, Expression and neural control of myogenic regulatory factor genes during regeneration of mouse soleus, J. Histochem. Cytochem. 7 (49) (2001) 887-899.

[72] A.N. Alves, B.G. Ribeiro, K.P. Fernandes, N.H. Souza, L.A. Rocha, F.D. Nunes, S.K. Bussadori, R.A. Mesquita-Ferrari, Comparative effects of low-level laser therapy pre- and post-injury on mRNA expression of MyoD, myogenin, and IL-6 during the skeletal muscle repair, Lasers Med. Sci. 31 (4) (2016 May) 679-685.

[73] M.J. Marques, A.P. Taniguti, E. Minatel, H.S. Neto, Nerve terminal contributes to acetylcholine receptor organization at the dystrophic neuromuscular junction of $\mathrm{mdx}$ mice, Anat. Rec. 290 (2) (2007 Feb) 181-187.

[74] M.M. Iyomasa, E.C. Rizzi, J.C. Leão, J.P. Issa, F.J. Dias, Y.C. Pereira, M.J. Fonseca, F.T Vicentini, I.S. Watanabe, Zymographic and ultrastructural evaluations after lowlevel laser irradiation on masseter muscle of HRS/J strainmice, Lasers Med. Sci. 28 (3) (2013 May) 777-783.

[75] P.C.L. Silveira, L.A. Silva, C.A. Pinho, P.S. Souza, M.M. Ronsani, D. Scheffer, R.A. Pinho, Effects of low-level laser therapy (GaAs) in an animal model of muscular damage induced bytrauma, Lasers Med. Sci. 2013 (28) (2013) 431-436.

[76] D. Pastore, M. Greco, S. Passarella, Specific helium-neon laser sensitivity of the purified cytochrome $c$ oxidase, Int. J. Radiat. Biol. 76 (6) (2000 Jun) 863-870.

[77] K. Nouette-Gaulain, C. Dadure, D. Morau, C. Pertuiset, O. Galbes, M. Hayot, et al., Age dependent bupivacaine-induced muscle toxicity during continuous peripheral nerve block in rats, Anesthesiology 111 (5) (2009 Nov) 1120-1127.

[78] R. Padera, E. Bellas, J.Y. Tse, D. Hao, D.S. Kohane, Local myotoxicity from sustained release of bupivacaine from microparticles, Anesthesiology 108 (5) (2008 May) 921-928.

[79] C.H. Cherng, C.S. Wong, C.T. Wu, C.C. Yeh, Intramuscular bupivacaine injection dosedependently increases glutamate release and muscle injury in rats, Acta Anaesthesiol. Taiwanica 48 (1) (2010 Mar) 8-14.

[80] W. Zink, B.M. Graf, Local anesthetic myotoxicity, Reg. Anesth. Pain Med. 29 (4) (2004 Jul-Aug) 333-340

[81] W. Zink, B. Sinner, Y. Zausig, B.M. Graf, Myotoxicity of local anaesthetics: experimental myth or clinical truth? Article in German. Anaesthesist. 56 (2) (2007 Feb) 118-127.

[82] N.A. Friel, V.M. Wang, M.A. Slabaugh, F. Wang, S. Chubinskaya, B.J. Cole, Rotator cuff healing after continuous subacromial bupivacaine infusion: an in vivo rabbit study, J. Shoulder Elb. Surg. 22 (4) (2013 Apr) 489-499. 